\title{
Analysing Navigators' Eye Movements by Utilizing Eye Mark Recorder on the Ship Handling Simulator
}

\author{
Serdar KUM*, Masao FURUSHO** and Özcan ARSLAN***
}

\begin{abstract}
This study clarifies the results of eye movement (view points) of navigators by utilizing the Istanbul Technical University Maritime Faculty (ITUMF) Ship Handling Simulator (SHS). The main objective is to define view points of navigator on the bridge and is based upon their sea experience and educational level. Finally, to evaluate view points, fixation durations and changes in view points.

A measurement device "Eye Mark Recorder, EMR-8" is used for recording the eye movements of subjects. The subjects are classified, according to their onboard experience level, into three groups. The same scenario, passing Istanbul Strait, was given to each subject on SHS. The general field was divided into three parts; "inside", "outside" and "others". The inside field has three components; instruments, indicator and engine telegraph. On the other hand, the outside field has three components; sea condition, navigational aids and target ships. "Others" means that all meaningless images and saccade of eye movements. Their view points and fixation durations are recorded by EMR-8 instrument, and then the data was analysed by using "Frame by Frame" method. Results were obtained and also compared with differences among these groups.

Group 1's fixation duration on the meaningless places and also "others" is so much longer than other groups. They have little experience in using the inside equipment. There was a remarkably big difference of fixation duration between the inside and outside field. Group 2 has a tendency to behave as the professionals in the general field. But their interest to inside field is higher than third group's. Group 3 paid proper attention to all the navigational information, not only nautical instruments, but also target ships and navigational aids. Finally, the effect of sea experience and training level on navigator is evaluated by utilizing the eye movements while carrying out simulator experience.
\end{abstract}

Keywords: eye movements, fixation duration, human factors

\section{Introduction}

Human (operator) error is a continuous factor inside of the casual chain. Human influences can't be removed in the design or operation of a ship, or its systems. Human factors have an important role in the operation of systems. The modern-day bridge is a complex mix of physical, psychological and pathological variables; all can impact on human performance. E.g. nowadays most bridges have an integrated navigation system or more complex, but give useful instruments for navigators. That's why the authors decided to carry such research by observing navigators' behaviours on the bridge. It will aid to understand that navigators may focus more in some areas (information) than in others.

To analyse the navigators' eye movements, the same environmental conditions were in each scenario. Eye movements were recorded by using EMR-8 instrument. After, data was analysed by using "Frame by Frame" method to get fixation durations based on the areas mainly categorized by inside and outside of the bridge.

\section{Experimental Study}

\subsection{The Profile of Subjects}

The subjects are classified according to their onboard experience level and then put into three groups. Each group has 4 subjects, total of 12 subjects in these experiments.

Group 1 consists of second year students of ITUMF and is called "beginner". They have only 2.5 months of onboard experience (mainly focused on deck tasks) and have just finished first year of maritime education. They get onboard as a first term cadet. The aim is not yet to catch bridge tasks and equipment. They haven't much knowledge of navigation and the operation of navigational equipment; not only reality, but also in SHS, because they haven't had any lessons on simulator. They are therefore the most unfamiliar group to SHS.

Group 2 consists of fourth year student of ITUMF and is called "candidate". They have just finished all compulsory on board training (12 months). They have chance to be able to enter the Ocean Going Watchkeeping Officer examination, to get this degree. By now they have enough knowledge about

\footnotetext{
* Member: Graduate School of Science and Technology, Kobe University, Fukae, Higashinada, Kobe 658-0022

** Member: Faculty of Maritime Sciences, Kobe University, Fukae, Higashinada. Kobe 658-0022 Japan

*** Not Member: Maritime Faculty, Istanbul Technical University, Tuzla. Istanbul 34940 Turkey
} 
navigation and the operation of equipment; not only reality, but also in SHS. They have enough bridge experience to sail and operate a ship. Also they have had knowledge about almost all subjects related to navigation and the simulator. They have had some lessons by utilizing SHS and they know how to operate it. They therefore have knowledge to operate the equipment and are familiar with the SHS.

Group 3 consists of Captains who are already Ocean Going Masters and have long sea experience. Almost all of them have had some task related to the SHS. E.g. instructor, researches, responsibility of some courses carried out through the SHS, and so on. They therefore have more knowledge and experience than the other groups. Their experience on operating real equipment is the highest. Also they are the most familiar group to the SHS. On the other hand they have mainly focused on the management side of the SHS. That's why they may not be of the same level with Group 2 about actually the operating equipment. Based on operating level, they should be the average of the other groups. Table 1 shows the characteristics of the Groups.

Table 1 The Characteristics of Subjects

\begin{tabular}{|l|c|c|c|}
\hline & $\begin{array}{c}2^{\text {nd }} \text { Year } \\
\text { Student }\end{array}$ & $\begin{array}{c}4^{\text {th }} \text { Year } \\
\text { Student }\end{array}$ & Captain \\
\hline Age & 19 & 21 & 40 \\
\hline $\begin{array}{l}\text { Number of } \\
\text { Subjects }\end{array}$ & 4 & 4 & 4 \\
\hline $\begin{array}{l}\text { Onboard } \\
\text { Experience }\end{array}$ & $\begin{array}{c}2.5 \\
\text { months }\end{array}$ & $\begin{array}{c}12 \\
\text { months }\end{array}$ & $\begin{array}{c}10 \\
\text { years }\end{array}$ \\
\hline Level & None & $\begin{array}{c}\text { Watchkeeping } \\
\text { Officer }\end{array}$ & Master \\
\hline $\begin{array}{l}\text { Knowledge } \\
\text { about SHS }\end{array}$ & None & Operation & Instructor \\
\hline
\end{tabular}

\subsection{Ship Handling Simulator - SHS}

The SHS system was installed into ITUMF in 2002 as an activity of project for the improvement of Maritime Education Training in Turkey and executed by ITUMF and the Japan International Cooperation Agency (JICA).

SHS is a system which realizes a realistic navigation condition both visually and audibly. It creates many navigational situations and in various types of vessel and with various environmental conditions. The ITUMF Ship Handling Simulator can provide many types of training and its advanced functions are as follows;

(1) Area creating/editing function; users can create/edit the areas wherever they want to execute training. It contains the functions to define many an environmental condition such as with $3 \mathrm{D}$ views, navigational aids, fenders, bollards, depths, currents, winds, wave, etc.

(2) Traffic flow creating/editing function; users can create/edit any density of traffic flow and with a variety kind/size of vessels such as container ships, tankers, bulk carriers, car carriers, fishing boats, etc.

(3) Scenario creating/editing function; users can create the training scenarios easily by combining the data of areas and traffic flows. Users can edit those created scenarios easily to satisfy the requirements of the clients or themselves.

Fig. 1 shows the general view of the Ship Handling Simulator of the Maritime Faculty, Istanbul Technical University.

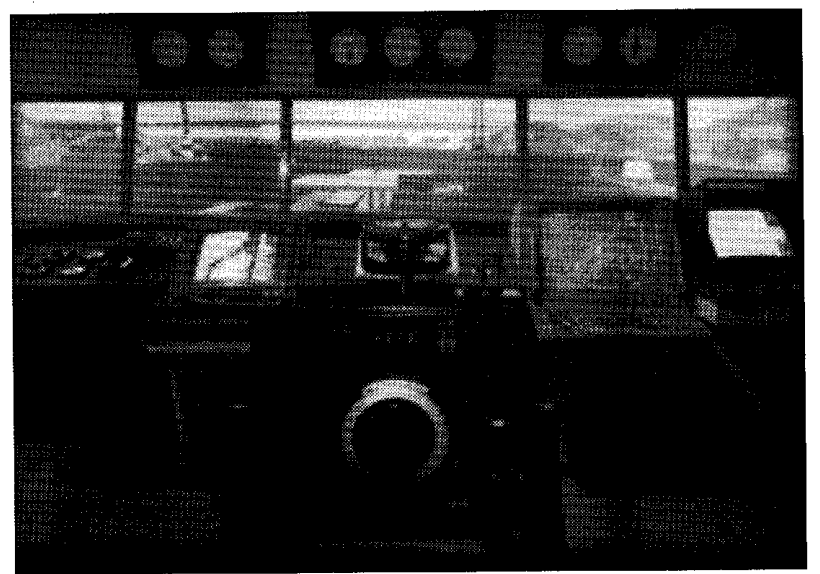

Fig. 1 ITUMF Ship Handling Simulator

\subsection{Eye Mark Recorder - EMR}

The eye mark recorder is a tool for detecting subjects' eye movement and recording the view points with coordinate data on PC and/or VTR (Video Tape Recorder) continuously, and combined together with viewing images. (In 2002 it was provided to ITUMF by the JICA project).

The EMR system consists of head cap unit, controller, PC, and VTR as shown in Fig. 2.

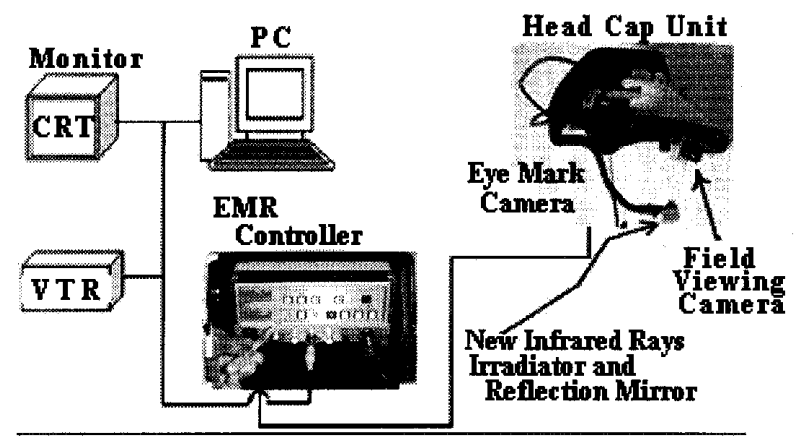

Fig. 2 The General Arrangement of EMR-8

\subsection{Experimental Condition}

All subjects were equipped with the EMR-8 instrument (head cap unit) as shown in Fig. 3, and executed the same scenario (ship type, ship speed, traffic condition and the environmental conditions are the same for all subjects). 


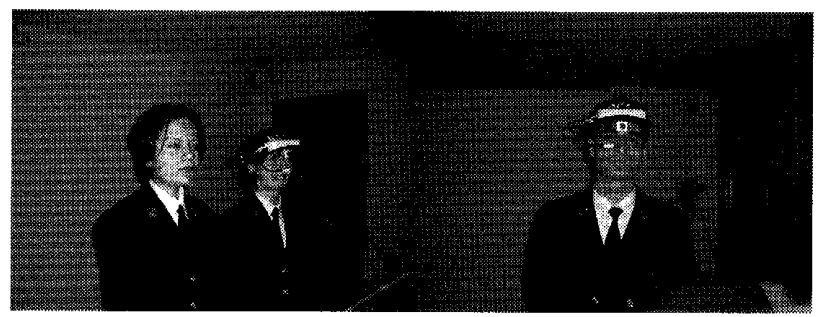

Fig. 3 The Fitting of Head Cap Unit of EMR-8

During the scenarios, there were two persons on board. One of them was the subject equipped with a head cap unit. He/she could move freely and also could move his/her head without any restrictions. The other person was a helmsman who was provided by authors. The helmsman has never placement with the subjects. Due to all subjects should not know the details of scenarios.

While subjects had control the ship no one interfered in scenario till authors stopped time. The time of scenarios was 10 minutes. Fig. 4 shows the conditions of subjects during scenario.

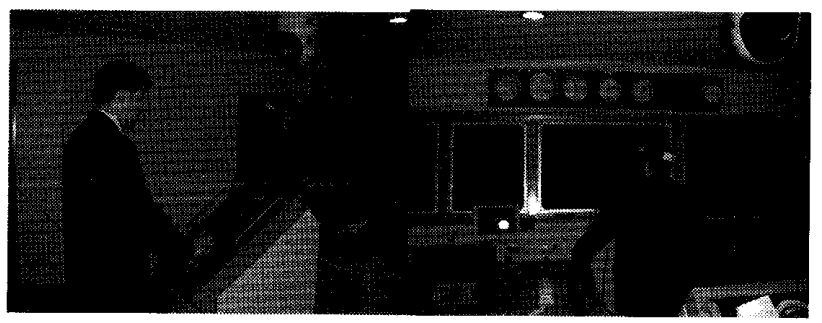

Fig. 4 Experimental Study by Using EMR-8

\subsection{Analysing Method}

Raw data cannot be analyzed by using the software of the EMR-8. Because the data includes head motion, then therefore an advanced analyzing method is used: "Frame-by-Frame Method".

In the analyzing it is important to divide the data into detailed analysis by using as much as possible of the categorized view area. That's why the authors have divided the data and visual images into 3 main categories, and 6 sub-categories in general field as shown in Fig. 5 and Fig. 6.

In analysing the authors focused on the place of the view points and fixation duration in the SHS scenarios.

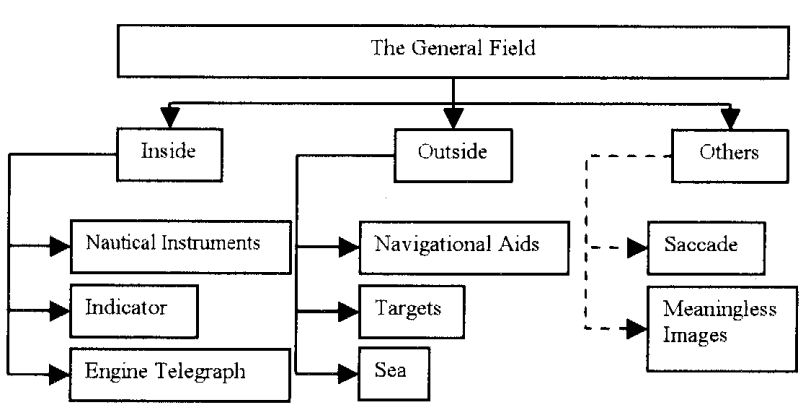

Fig. 5 The Categories of Visual Images

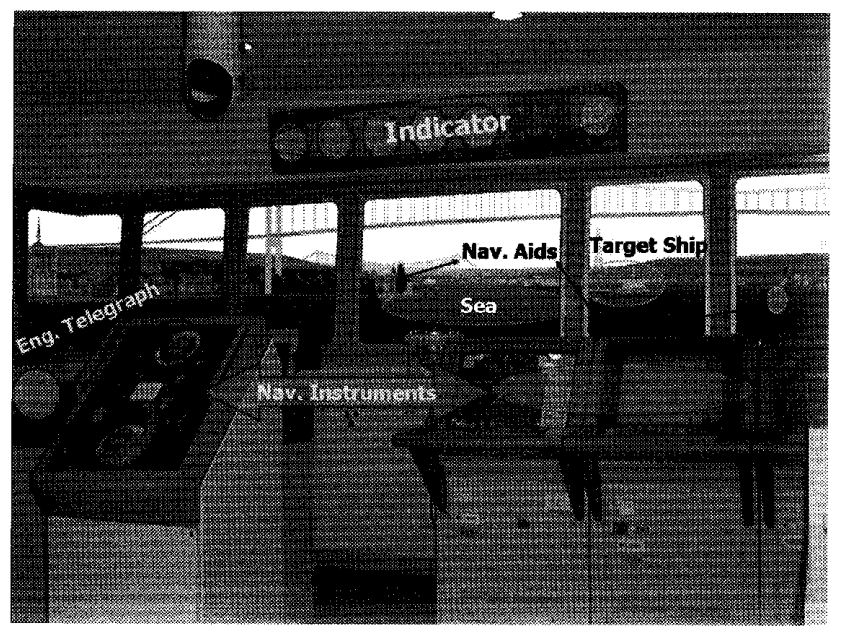

Fig. 6 The General Field of SHS Scenario

\section{Results and Consideration}

The results obtained from Frame by Frame used Microsoft Excel. The results were considered as, firstly the situation in the own group (for every subject and the average of own group), then the situation between the other groups and own group for each category. Finally, to consider all results in the main categories, and evaluating the fixation durations in three levels ("excessive", "normal" and "low fixation") is based on their view percentage as shown in Table 2. This means that this classification depends on their behaviour, e.g. if the level of fixation duration is "excessive" for one category, the subject(s) give more lookouts (viewings) and spend more time than with the other categories, this based on the average and standard deviation of view points.

Table 2 The Percentage of Fixation Duration

\begin{tabular}{|c|c|c|c|c|c|c|c|c|c|c|}
\hline & \multicolumn{3}{|c|}{ INSIDE (\%) } & \multicolumn{3}{|c|}{ OUTSIDE (\%) } & \multirow{2}{*}{$\begin{array}{c}\text { Others } \\
(\%)\end{array}$} & \multirow{2}{*}{$\begin{array}{c}\text { Average } \\
(\%)\end{array}$} & \multirow{2}{*}{$\begin{array}{c}\text { STDEV } \\
(\%)\end{array}$} & \\
\hline & Nautical Inst. & Indicator & Eng. Telg. & Nav. Aids & Target Ship & Sea & & & & \\
\hline \multirow{2}{*}{ Group 1} & 31.6 & 3.4 & 2.6 & 7.8 & -3.6 & 36.4 & 14.6 & 14.3 & 14.1 & \multirow{2}{*}{ Excessive } \\
\hline & \multicolumn{3}{|c|}{37.6} & \multicolumn{3}{|c|}{47.8} & 14.6 & 33.3 & 17.0 & \\
\hline \multirow{2}{*}{ Group 2} & 53.7 & 6.7 & 0.0 & 7.2 & 2.0 & 26.1 & 4.3 & 14.3 & 19.4 & \multirow{4}{*}{$\begin{array}{l}\text { Normal } \\
\text { Fixation }\end{array}$} \\
\hline & \multicolumn{3}{|c|}{60.4} & \multicolumn{3}{|c|}{35.3} & 4.3 & 33.3 & 28.1 & \\
\hline \multirow{2}{*}{ Group 3} & 42.2 & 3.9 & 0.0 & 12.5 & 8.5 & 24.4 & 8.5 & 14.3 & 14.5 & \\
\hline & & (2) & & & $4=$ & 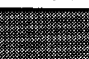 & 8.5 & 33.3 & 21.5 & \\
\hline \multirow{2}{*}{ TOTAL } & 42.5 & 4.7 & 0.9 & 9.2 & 4.7 & 28.9 & \multirow{2}{*}{9.1} & 14.3 & 15.4 & \multirow{2}{*}{ Low } \\
\hline & \multicolumn{3}{|c|}{48.1} & \multicolumn{3}{|c|}{42.8} & & & & \\
\hline
\end{tabular}


Table 3 summarizes the results based on comparisons in the group members and among groups in the general field and the inside field and/or outside field.
Table 3 also shows the fixation levels of groups based on the tendency of subjects' view points in the general field and all groups.

Fig. 7 shows the ratio of fixation duration of all groups. And, Fig. 8 and Table 4 shows the fixation duration based on main categories among the groups.

Table 3 The Results and Considerations of Fixation Duration to Categories of the Groups

\begin{tabular}{|c|c|c|c|c|c|c|c|}
\hline & \multicolumn{2}{|c|}{ GROUP 1} & \multicolumn{2}{|c|}{ GROUP 2 } & \multicolumn{2}{|c|}{ GROUP 3 } \\
\hline & & In the Group & Among the Groups & In the Group & Among the Groups & In the Group & Among the Groups \\
\hline \multirow{3}{*}{ 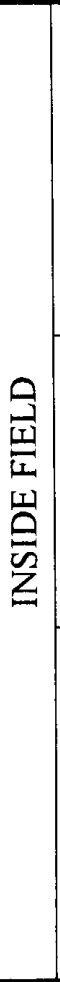 } & 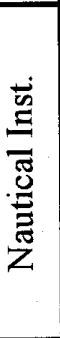 & $\begin{array}{l}\text { - big } \\
\text { difference }\end{array}$ & $\begin{array}{l}\text { - the lowest fixation } \\
\text { duration in inside } \\
\text { field }(84.0 \%) \\
\text { - the lowest fixation } \\
\text { duration in general } \\
\text { field }(31.6 \%) \\
\text { - "excessive fixation" }\end{array}$ & - similarity & $\begin{array}{l}\text { - the middle fixation } \\
\text { duration in inside } \\
\text { field }(88.9 \%) \\
\text { - the highest fixation } \\
\text { duration in general } \\
\text { field }(53.7 \%) \\
\text { - "excessive fixation" }\end{array}$ & - similarity & $\begin{array}{l}\text { - the highest fixation } \\
\text { duration in inside } \\
\text { field }(91.5 \%) \\
\text { - the middle fixation } \\
\text { duration in general } \\
\text { field }(42.2 \%) \\
\text { - Between normal and } \\
\text { excessive fixation }\end{array}$ \\
\hline & 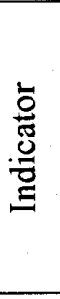 & - similarity & $\begin{array}{l}\text { - the middle fixation } \\
\text { duration in inside } \\
\text { field }(9.2 \%) \\
\text { - the lowest fixation } \\
\text { duration in general } \\
\text { field } \\
\text { - "low fixation" }\end{array}$ & $\begin{array}{l}\text { - small } \\
\text { difference }\end{array}$ & $\begin{array}{l}\text { - the highest fixation } \\
\text { duration in inside } \\
\text { field (11. 1\%) } \\
\text { - the highest fixation } \\
\text { duration in general } \\
\text { field } \quad(6.7 \%) \\
\text { - "normal fixation" }\end{array}$ & - similarity & $\begin{array}{l}\text { - the lowest fixation } \\
\text { duration in inside } \\
\text { field }(8.5 \%) \\
\text { - the middle fixation } \\
\text { duration in general } \\
\text { field } \\
\text { - "low fixation" }\end{array}$ \\
\hline & 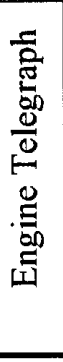 & - similarity & $\begin{array}{l}\text { - the lowest fixation } \\
\text { duration in the group } \\
\text { in inside and outside } \\
\text { field } \quad(6.8 \%) \\
\text { - the highest fixation } \\
\text { duration in inside } \\
\text { field and in general } \\
\text { field } \\
\text { - "low fixation" }\end{array}$ & $\begin{array}{l}\text { - similarity } \\
\text { - only one } n \\
\text { (necessary } f \\
\text { - "low fixat }\end{array}$ & $\begin{array}{l}\text { long the group memb } \\
\text { mber of Group } 3 \text { uses } \\
\text { using ) }\end{array}$ & ro to not uce & $\begin{array}{l}\text { igine } \\
\text { just only one time }\end{array}$ \\
\hline \multirow{3}{*}{ 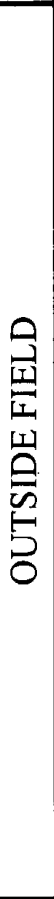 } & 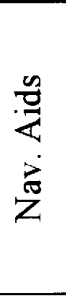 & - similarity & $\begin{array}{l}\text { - the lowest fixation } \\
\text { duration in outside } \\
\text { field }(16.2 \%) \\
\text { - the middle fixation } \\
\text { duration in general } \\
\text { field } \quad(7.8 \%) \\
\text { - "normal fixation" }\end{array}$ & $\begin{array}{l}\text { - small } \\
\text { difference }\end{array}$ & $\begin{array}{l}\text { - the middle fixation } \\
\text { duration in outside } \\
\text { field }(20.3 \%) \\
\text { - the lowest fixation } \\
\text { duration in general } \\
\text { field } \\
\text { - "normal fixation" }\end{array}$ & - similarity & $\begin{array}{l}\text { - the highest fixation } \\
\text { duration in outside } \\
\text { field }(27.5 \%) \\
\text { - the highest fixation } \\
\text { duration in general } \\
\text { field (12. 5\%) } \\
\text { - "normal fixation" }\end{array}$ \\
\hline & 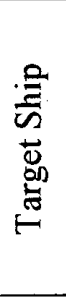 & - similarity & $\begin{array}{l}\text { - the middle fixation } \\
\text { duration in outside } \\
\text { field }(7.6 \%) \\
\text { - the middle fixation } \\
\text { duration in general } \\
\text { field } \\
\text { - "low fixation" }\end{array}$ & & $\begin{array}{l}\text { - the lowest fixation } \\
\text { duration in outside } \\
\text { field }(5.8 \%) \\
\text { - the lowest fixation } \\
\text { duration in general } \\
\text { field } \\
\text { - "low fixation" }\end{array}$ & $\begin{array}{l}\text { - small } \\
\text { difference }\end{array}$ & $\begin{array}{l}\text { - the highest fixation } \\
\text { duration in outside } \\
\text { field }(18.8 \%) \\
\text { - the highest fixation } \\
\text { duration in general } \\
\text { field } \\
\text { - "normal fixation" }\end{array}$ \\
\hline & ஜ & $\begin{array}{l}\text { - big } \\
\text { difference }\end{array}$ & $\begin{array}{l}\text { - the highest fixation } \\
\text { duration in outside } \\
\text { field }(76.2 \%) \\
\text { - the highest fixation } \\
\text { duration in general } \\
\text { field (36. 4\%) } \\
\text { - "excessive fixation" }\end{array}$ & - similarity & $\begin{array}{l}\text { - the middle fixation } \\
\text { duration in outside } \\
\text { field }(73.9 \%) \\
\text { - the middle fixation } \\
\text { duration in general } \\
\text { field } \quad(26.1 \%) \\
\text { - "excessive fixation" }\end{array}$ & $\begin{array}{l}\text { - small } \\
\text { difference }\end{array}$ & $\begin{array}{l}\text { - the lowest fixation } \\
\text { duration in outside field } \\
\text { (53. 7\%) } \\
\text { - the lowest fixation } \\
\text { duration in general field } \\
\text { (24. } 4 \%) \\
\text { - Between normal and } \\
\text { excessive fixation }\end{array}$ \\
\hline & LND & - difference & $\begin{array}{l}\text { - the highest fixation } \\
\text { duration (14.6\%) } \\
\text { - "low fixation" }\end{array}$ & $\begin{array}{l}\text { - strong } \\
\text { similarity }\end{array}$ & $\begin{array}{l}\text { - the lowest fixation } \\
\text { duration } \quad(4.3 \%) \\
\text { - "low fixation" }\end{array}$ & - similarity & $\begin{array}{l}\text { - the middle fixation } \\
\text { duration } \quad(8.5 \%) \\
\text { - "low fixation" }\end{array}$ \\
\hline
\end{tabular}




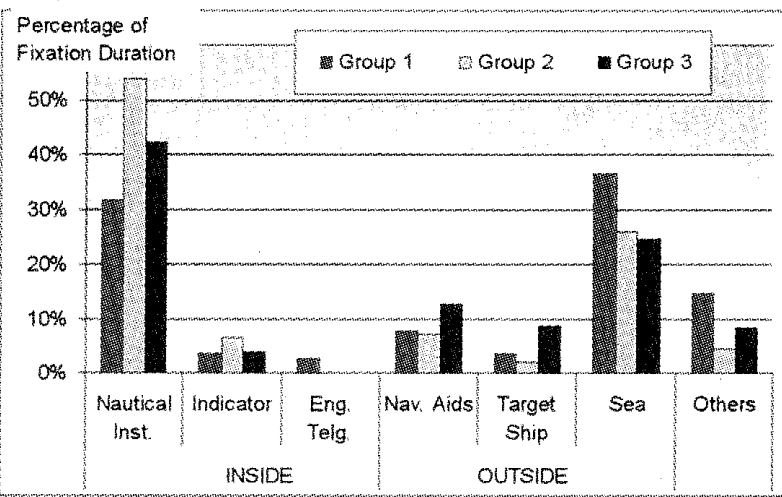

Fig. 7 The Distribution of Fixation Duration among the Visual Images

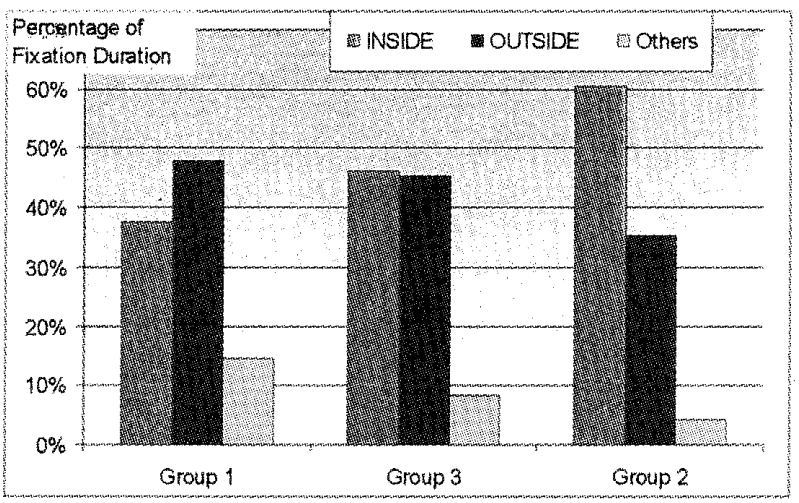

Fig. 8 The Comparison of Inside and Outside Fields among the Groups

Table 4 The Fixation Levels of Groups depend on Main Categories

\begin{tabular}{|c|c|c|c|}
\hline & INSIDE & OUTSIDE & OTHERS \\
\hline Group 1 & $\begin{array}{l}\text { The lowest fixation duration, } \\
\text { "normal fixation" } \quad(37.6 \%)\end{array}$ & $\begin{array}{l}\text { The highest fixation duration, } \\
\text { "excessive fixation" (47.8\%) }\end{array}$ & $\begin{array}{l}\text { The highest fixation duration, } \\
\text { "low fixation" } \quad(14.6 \%)\end{array}$ \\
\hline Group 2 & $\begin{array}{l}\text { The highest fixation duration. } \\
\text { "excessive fixation" } \quad(60.4 \%)\end{array}$ & $\begin{array}{l}\text { The lowest fixation duration, } \\
\text { "normal fixation" } \quad(35.3 \%)\end{array}$ & $\begin{array}{l}\text { The lowest fixation duration, } \\
\text { "low fixation" } \\
\end{array}$ \\
\hline Group 3 & $\begin{array}{l}\text { The ratio of inside }(46.1 \%) \text { and } \\
\text { That's why fixation is between ex }\end{array}$ & $\begin{array}{l}\text { outside }(45.4 \%) \text { is almost same. } \\
\text { xcessive and normal fixation }\end{array}$ & $\begin{array}{l}\text { The middle fixation duration, } \\
\text { "low fixation" } \\
\text { (8. } 5 \%)\end{array}$ \\
\hline
\end{tabular}

According to the results of experimental study and shown in Table 2, Fig. 7 and Fig. 8; the remarkable points can be obtained as follows;

\section{(1) Group 1;}

While two members had fixation duration (in the general field) at over $50 \%$, the other two members' was only around $5 \%$ for the nautical instruments. There is an inconsistency among group members. The reason for this can be explained as; some of them don't know the operation, so they should focus their attention for understanding the equipment (human behaviour has an intention to learn unknown things); As for the others, they don t know how to operate, and so spend their attention to what they do know (human behaviour does not give much intention to things are not been known). If they focused inside, the highest fixation duration would be towards nautical instruments, or if they focused outside, they would have to spend their all time towards the sea. The lowest fixation duration toward nautical instruments belongs to this group in both inside and the general field. This is the expected result; due to minimal knowledge and experience.

Group 1 focuses the indicator more than Group 3 in the inside field, but in the general field they are the last group whose fixation duration to indicator is the lowest. These all verify assumptions for the first group. They haven't enough skill to perceive the general situation. That's why they don't need to care about indicator trough viewings in the inside field. But when they look at it, they do spend more time to understand.
Almost all members of Group 1 want to use engine telegraph. It shows that they are unnecessary users.

Group 1 has the lowest fixation to navigational aids in the outside field, but it is middle of the other groups in the general field. In here it will be true to make this assumption. According to ITUMF curriculum first year students have basic lessons related to navigational (terrestrial navigation and navigational aids). They try to execute this training during experimental study, but their interest is more than Group 2 in general field, due to not having enough experience to perceive all images.

\section{(2) Group 2;}

Fixation duration to nautical instruments in the general field is in the first tier, and there is big difference with the other categories. It shows that their training on navigational equipment is of a good level.

They spend their attention mainly to the nautical instruments. But their perception is less than the professionals' perception; that's why their interest is inside rather than outside. This verifies their profile and as related with using the equipment.

They have fewer ratios $(7.2 \%)$ of fixation duration to navigational aids in the general field than Group 1. In here, this assumption can also be made for this group; they are under to forget the training, due to the related subjects are trained till the end of second year. Or, after training the use of information is based on human, that's why some of them give more attention, when the others give almost any attention to navigational aids. On the other hand the number of subjects is not enough to make this assumption 
generally. But if the tendency of all members is the same pattern, it is expected that second group's fixation duration would be middle of the groups, not only in the outside field but also in the general field.

\section{(3) Group 3:}

Group 3 has the highest fixation duration to nautical instruments in the inside field, but in the general field their ratio is middle. It shows that they balance the fixation to not only one area, but also the other areas. Nautical instruments are the most importance information source in the inside field. Outside field or information can be perceived through this source.

Their fixation duration to indicator is the lowest and Group 3 is faster to understand what they look at than the others. And also in the general field they give less attention to indicator as do the other groups. They don't spend much time to look and also there is not any delay in perception.

Only one member used the engine, but it was just only one time. This shows that if a necessary situation for using engine it should be used, but not for every situation.

The members of Group 3 have different fixations to target ships by comparing with the other groups. E.g. one of the members almost has no interest in the target ship; the other has the highest interest in all members of groups. It makes the variance to increasing in this group. Otherwise, they have similar patterns with the other groups to have lower fixation duration on the target ship.

\section{Conclusions}

There are some differences among the ratios of fixation durations in the general field, but the tendency is the same for all groups (Fig. 7) and the order (high to low fixation with the average ratios in general field) is; nautical instruments $(42.5 \%)$, sea $(28.9 \%)$, navigational aids $(9.2 \%)$, indicator $(4.7 \%)$, target ship (4.7\%) and engine telegraph $(0.9 \%)$. It shows that the navigator firstly cares to the inside field (bridge) and then he/she tries to perceive outside field for understanding the situation of him/her. When navigator focuses inside field, the nautical instruments are the first priority to get information. And also we can get one remarkable point that if the view points and fixation duration are the similar ratio in inside and outside field (the balance between images of inside and outside); it looks like a professional behaviour. Then understanding situation and to be able to protect the situational awareness in navigation. The behaviour of Group 3 (the ratio of inside field is $46.1 \%$, outside is $45.4 \%$ ) verifies this idea as a professional group.

On the other hand, lessening of educational level and sea experience decreases the using of nautical instruments and decreases the information perception from them. Group 1 has the lowest fixation to nautical instruments with the ratio of $31.6 \%$ in general field. When the educational level becomes higher but sea experience is almost same level, the fixation duration to nautical instruments takes more time. The fixation to nautical instruments in Group 2 is middle in inside field but it is the highest in general field at $53.7 \%$ among the groups. These are also the behaviour of an amateur navigator.

Finally, the more sea experience, the fast a perception on relation between events and the better control of situation. On the other hand, the authors consider restriction of the number of subjects, that's why it is necessary to carry and more such experimental studies for better understanding and evaluating of navigators' behaviours.

\section{References}

(1) Arslan, O., Furusho, M. and Kum, S., Evaluating Sea Experience with an Eye Mark Recorder in a Ship Handling Simulator, IAMU AGA-6 Proceedings, Section 3, pp.313-319, 2005

(2) CIE Publication №17.4 『International Lighting Vocabulary』845-02-57/p.62, CIE1987

(3) M.Yamada and T. Fukuda, 『An Improved SightLine Displacement Analyzer and Its Application to TV Program Production』, SMPTE Journal p.22, Jan. 1990

(4) Michael W. Eysench and Mark Keane, Cognitive Psychology $4^{\text {th }}$ edition, Psychology Press, p.64, 2000, ISBN 0-86377-551-9

\section{Questions and Answers}

Kozaburo YAMADA (Retired from Hitachi Zosen): While navigator is looking out, he/she sees the "Sea" area with land. In your study, do you count the fixation durations on land in the category of "Sea" or "Others"?

Serdar KUM: By the categorized visual area, "Sea" covers the sea surface; landmarks, light houses etc. are categorized as "Navigational Aids" and the other parts of the land can not be considered.

\section{Comments}

Yoshinari OKANO (National Institute for Sea Training): Time spent to three items (Nav. Aids, Sea, Others) seems like an eye movements for "Look-Out". It is suggested that attention should be paid to the point of "Look-Out".

Serdar KUM: The aim is to find that navigator looks where and what is the priority of this place among the visual field. "Look-Out" means the searching of eye movements and when the subject is found, navigator focuses to it. On the other hand for analysing of data by using "Frame by Frame" method, the visual field should be more categorized. When we categorized "Look-Out" in three or more fields, we can make detail consideration for these categories and to compare of them. 